\title{
Zonasi kawasan perkotaan berbasis mitigasi bencana banjir (Studi kasus Kota Denpasar)
}

\author{
Ninda Irmayanti ${ }^{1}$, Indayati Lanya ${ }^{2 \star}$, Ni Wayan Febriana Utami ${ }^{1}$ \\ 1. Prodi Arsitektur Pertamanan, Fakultas Pertanian, Universitas Udayana, Indonesia 80232 \\ 2. Prodi Agroekoteknologi, Fakultas Pertanian, Universitas Udayana, Indonesia 80232 \\ *E-mail : indayatilanya@unud.ac.id
}

\begin{abstract}
Abtract
Urban zoning based of flood disaster mitigation (case study in Denpasar City). Denpasar City has been experienced a calamitous event such as flooding or inundating caused by development activities and topographical conditions of urban areas which prone to risk to flood disasters. Therefore, urban planning in Denpasar City needs to be handled by developing the concept of flood mitigation approach by considering the level of risk and the characteristics of the city of Denpasar. The purpose of this research was to develop zoning concept in urban areas based on flood mitigation approach. The method used in this study was overlaying analysis and descriptive analysis. The results showed that the level of flood vulnerability in Denpasar city was increased from $59.62 \%$ in 2015 and reached to $61.24 \%$ in 2016. The trends caused by a high rainfall during 2016 and was influenced by the hydrogeological characteristics, slope and land use change. Based on spatial analysis, the concept of flooding mitigation formed as follows: 1) high hazard zone (refers to the concept of disaster mitigation in a high hazard area); 2) Medium hazard zone (referring to the concept of disaster mitigation in medium hazard area); 3) Low hazard zone (referring to the concept of disaster mitigation in low hazard area). In conclusion it recommended that the government and the community need to work together while maintaining the environment and monitoring the use of space in the urban area. Further research is needed related to hydraulic conditions so that results are more valid.
\end{abstract}

\section{Keywords : flood, Denpasar City, disaster mitigation, urban, zoning}

\section{Pendahuluan}

Kota Denpasar merupakan ibu kota Provinsi Bali, sekaligus sebagai pusat pemerintahan, pendidikan, maupun perekonomian. Oleh sebab itu, masalah umum di perkotaan seperti peningkatan jumlah penduduk dan kebutuhan tempat tinggal tidak dapat dihindari berdampak pada semakin banyak area terbangun didirikan di perkotaan. Seperti yang diungkapkan oleh Salain (2015) bahwa Kota Denpasar pernah mengalami banjir di beberapa wilayah akibat pembangunan yang over capacity, yakni hampir 60 persen luasan Kota Denpasar adalah bangunan beton bukan lahan terbuka hijau. Kota Denpasar mengalami fenomena terkait bencana banjir atau genangan yang cukup signifikan diakibatkan adanya pemanfaatan ruang yang kurang terkendali dan dari kegiatan pembangunan serta kondisi topografi Kota Denpasar di daerah hilir rawan terhadap risiko bencana banjir. Kondisi Kota Denpasar seperti yang telah dijelaskan maka perlu adanya mitigasi agar tidak mengakibatkan kerusakan lingkungan yang berdampak pada aktivitas masyarakat. Oleh karena itu, perencanaan kawasan perkotaan perlu ditangani dengan mengembangkan konsep mitigasi bencana banjir melalui pendekatan zonasi yang tepat dengan mempertimbangkan tingkat risiko dan karakteristik Kota Denpasar. Berdasarkan latar belakang tersebut, rumusan masalah dari penelitian ini yaitu untuk mengetahui bagaimana karakteristik fisik Kota Denpasar sehingga dapat menghasilkan konsep mitigasi bencana banjir dengan berbasis sistem informasi geografis (SIG). Penelitian ini bertujuan untuk menentukan zonasi kawasan perkotaan berdasarkan bahaya bencana banjir sebagai suatu upaya pencegahan bencana banjir di Kota Denpasar. 
2. Metode Penelitian

2.1 Waktu dan Tempat

Waktu penelitian dilaksanakan bulan Februari 2017 sampai dengan bulan Mei 2019. Tempat penelitian di Kota Denpasar, Provinsi Bali. Lokasi penelitian disajikan pada Gambar 1.

\section{2}

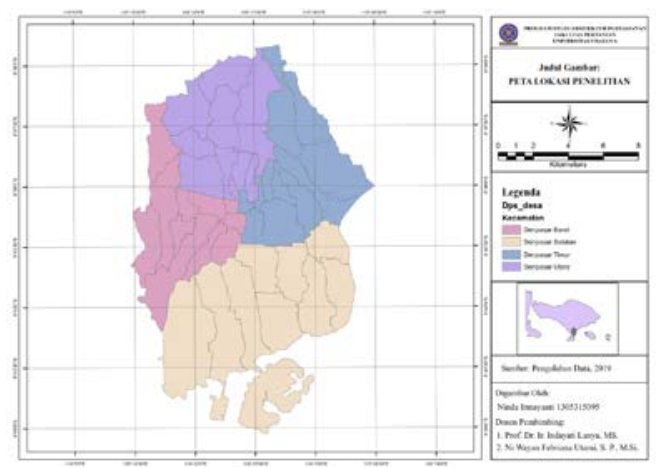

Gambar 1. Lokasi Penelitian

\section{Bahan dan Alat}

Bahan yang digunakan selama penelitian ini yaitu data spasial berupa citra satelit Landsat 8 tahun 2015 dan 2016, peta administrasi kota denpasar, peta rencana pola ruang, peta geologi, peta curah hujan, peta penggunaan lahan, peta hidrogeologi, dan data terkait regulasi zonasi. Alat yang digunakan yaitu perangkat keras berupa perangkat komputer, kamera ponsel, serta printer. Sedangkan perangkat lunak berupa QuantumGIS 2.18, ArcGIS 10.4, Adobe Photoshop, Google Earth pro 8, GPS Essentials, Microsoft Word 2013, Microsoft Excel 2013, dan Notepad.

\subsection{Jenis Data, Metode Pengumpulan Data, dan Analisis}

Jenis data yang diperlukan dalam penelitian ini adalah data primer dan data sekunder. Data primer diperoleh dengan observasi ke lokasi penelitian untuk mengambil dokumentasi serta titik koordinat sebagai sampel data uji akurasi klasifikasi penggunaan lahan dan peta penggunaan lahan dari hasil analisis digital citra satelit. Sedangkan data sekunder diperoleh dari earthexplorer.usgs.gov berupa citra satelit dan digital elevation model (DEM), data kejadian banjir dari Dinas Perkerjaan Umum (PU) Kota Denpasar, Peta Hidrogeologi Pulau Bali yang dikeluarkan oleh Direktorat Tata Lingkungan Geologi dan Kawasan Pertambangan, data curah hujan bulanan selama 2008 - 2017 di Pos Sanglah dan Pos Sumerta dari Balai Meteorologi dan Geofisika Wilayah III Denpasar, dan masterplan drainase dari Badan Perencanaan Pembangunan Daerah (Bappeda) Kota Denpasar. Sedangkan data pendukung lainnya diperoleh dari pustaka hasil penelitian, buku, media internet, dan dokumen ilmiah dari instansi terkait. Metode pengumpulan data yang digunakan oleh peneliti dalam mengumpulkan data yaitu: studi kepustakaan, observasi lapangan, dan wawancara lapangan.

Penelitian ini menggunakan metode penelitian analisis dengan tiga tahapan dimana setiap tahapan menggunakan metode analisis yang berbeda-beda antara lain: Tahap I. Analisis data menggunakan metode analisis spasial dan analisis deskriptif dari peta tematik yang tersedia. Analisis data spasial memanfaatkan Sistem Informasi Geografis (SIG) dengan menggunakan software QuantumGIS (QGIS) 2.18, ArcGIS 10.4, Google Earth pro 8, dan Microsoft Excel 2013 untuk mengolah data atribut dan data tabulasi. Data spasial yang digunakan merupakan peta tematik akan dilakukan proses pemasukan data dalam bentuk digital (dijitasi) untuk selanjutnya dilakukan proses tumpang susun (overlay). Analisis spasial menggunakan data Landsat ini perlu dilakukan uji akurasi sebelum data yang diperoleh dapat digunakan untuk berbagai macam tujuan. Akurasi ketelitian dalam pemetaan dilakukan dengan membuat matrik kesalahan (confusion matrix). Akurasi yang bisa dihitung berdasarkan Tabel 1 yang di dalamnya terdapat user's accuracy, producer's accuracy dan overall accuracy. 
Tabel 1. Matriks Kesalahan (Confusion Matrix)

\begin{tabular}{|c|c|c|c|c|c|c|}
\hline \multirow{2}{*}{ Data Referensi } & \multicolumn{4}{|c|}{ Data Kelas di Peta } & \multirow{2}{*}{ Jumlah } & \multirow{2}{*}{ Producer's accuracy } \\
\hline & $A$ & $B$ & $C$ & $\mathrm{D}$ & & \\
\hline A & $X$ & & & & $X_{i+}$ & $X_{i i} / X_{i+}$ \\
\hline \multicolumn{7}{|l|}{ B } \\
\hline \multicolumn{7}{|l|}{ C } \\
\hline D & & & & $X_{i i}$ & & \\
\hline Total Kolom & $X$ & & & & & \\
\hline User's accuracy & & & & & & \\
\hline
\end{tabular}

Jaya (2010) menambahkan bahwa saat ini akurasi ketelitian yang dianjurkan adalah akurasi Kappa atau indeks Kappa karena pada hasil overall accuracy memiliki hasil yang lebih dari perkiraan (over estimate). Rumusan matematis akurasi overall dan akurasi Kappa disajikan sebagai berikut:

$$
\begin{aligned}
& \text { User' accuracy }=\frac{\mathrm{x}_{i i}}{\mathrm{x}_{i+}} \times 100 \% \\
& \text { Producer's accuracy }=\frac{\mathrm{x}_{i i}}{\mathrm{x}_{i+}} \times 100 \% \\
& \text { Overall accuracy }=\frac{\sum_{i}^{r} \mathrm{X}_{i i}}{N} \times 100 \% \\
& \text { Kappa ( } \mathrm{k})=\frac{\sum_{i}^{r} \mathrm{x}_{i i}-\sum_{i}^{r} \mathrm{x}_{i+} \mathrm{X}_{+i}}{N^{2}-\sum_{i}^{r} \mathrm{x}_{i+} \mathrm{X}_{+i}} \times 100 \%
\end{aligned}
$$

Keterangan :

$\mathrm{N}=$ banyaknya piksel dalam contoh

$X_{\mathrm{ii}}=$ nilai diagonal matriks kontingensi baris ke-i dan kolom ke-i

$X_{i+}=$ jumlah piksel dalam baris ke- $\mathrm{i}$

$\mathrm{X}_{+\mathrm{i}}=$ jumlah piksel dalam kolom baris ke-i

Berikutnya, analisis dilanjutkan dengan analisis kondisi kebencanaan dengan metode analisis visual dan analisis deskriptif dari peta titik genangan banjir dan keadaan lapangan. Kemudian, analisis risiko

\begin{tabular}{|c|c|c|c|c|}
\hline No & Parameter & Bobot & Skor & Nilai \\
\hline \multirow[t]{4}{*}{1} & Kedalaman Air Tanah & \multirow{4}{*}{4} & & \\
\hline & a. Dangkal & & 3 & 12 \\
\hline & b. Sedang & & 2 & 8 \\
\hline & c. Dalam & & 1 & 4 \\
\hline \multirow[t]{4}{*}{2} & Kelerengan & \multirow{4}{*}{3} & & \\
\hline & a. $0-3 \%$ & & 3 & 9 \\
\hline & b. $3-5 \%$ & & 2 & 6 \\
\hline & c. $>5 \%$ & & 1 & 3 \\
\hline \multirow[t]{4}{*}{3} & Curah Hujan (jumlah/bulan) & \multirow{4}{*}{2} & & \\
\hline & a. $164.4>$ & & 3 & 6 \\
\hline & b. $162.5-164.3$ & & 2 & 4 \\
\hline & c. $<162.5$ & & 1 & 2 \\
\hline \multirow[t]{4}{*}{4} & Penggunaan Lahan & \multirow{4}{*}{1} & & \\
\hline & a. Terbangun (Kerapatan Tinggi) & & 3 & 3 \\
\hline & b. Terbangun (Kerapatan Rendah) & & 2 & 2 \\
\hline & c. Lahan Terbuka/Hijau & & 1 & 1 \\
\hline
\end{tabular}
dilakukan dengan menggunakan analisis atribut dan dan analisis keruangan berdasarkan parameterparameter yang digunakan seperti pada Tabel 2 .

Tabel 2. Pembobotan Parameter-parameter Banjir

Sumber: Lanya (2015) (telah dimodifikasi) 


\section{Hasil dan Pembahasan}

\subsection{Gambaran Umum Kota Denpasar}

Kota Denpasar terletak antara $08^{\circ} 35^{\prime} 31^{\prime \prime}-08^{\circ} 44^{\prime} 49^{\prime \prime}$ lintang selatan dan $115^{\circ} 10^{\prime} 23^{\prime \prime}-115^{\circ} 16^{\prime} 27^{\prime \prime}$ bujur timur, dan berbatasan dengan Kabupaten Badung di bagian utara, selatan dan barat serta Kabupaten Gianyar di bagian timur. Secara administratif, Kota Denpasar memiliki empat kecamatan dengan 43 desa. Kecamatan yang berada di Kota Denpasar terdiri dari Kecamatan Denpasar Timur dengan luas 22,31 km², Kecamatan Denpasar Selatan dengan luas 49,99 km², Kecamatan Denpasar Barat dengan luas 24,06 km², dan Kecamatan Denpasar Utara dengan luas 31,42 km². Sejak tahun 2007 hingga tahun 2016 bencana banjir yang pernah terjadi di Kota Denpasar selalu terulang setiap tahunnya di beberapa lokasi tertentu. Sebagai contoh pada 25 Desember 2007 terjadi genangan banjir yang terbilang cukup tinggi menggenang di wilayah perumahan Padang Asri, Monang Maning, Denpasar Barat. Genangan banjir serupa terjadi kembali di wilayah Monang Maning pada 19 Desember 2011, 14 Desember 2012, dan 28 Juni 2013. Wilayah itu sendiri sudah sering terjadi banjir sejak tahun 2007. Genangan banjir pada kawasan tersebut disebabkan oleh saluran drainase yang tidak lancar dan sempit sehingga tidak mampu mengalirkan limpasan air hujan dengan baik.

\subsection{Analisis}

\subsubsection{Analisis Kondisi Hidrogeologi}

Analisis kondisi hidrogeologi ini diperoleh dari data Peta Hidrogeologi Pulau Bali yang dikeluarkan oleh Direktorat Tata Lingkungan Geologi dan Kawasan Pertambangan. Hasil yang diperoleh dengan analisis data visual menunjukkan bahwa Kota Denpasar memiliki akifer bebas dan akifer semi tertekan atau tertekan. Berdasarkan data dari akifer air tanah di Kota Denpasar mengikuti pola Bali Selatan secara umum, terdiri dari dua kelompok yaitu akifer dangkal yang di dalamnya terdapat air tanah bebas dan akifer dalam yang di dalamnya terdapat air tanah tertekan atau semi tertekan. Akifer dangkal ditemukan pada kedalaman $30-50$ $\mathrm{m}$ dengan formasi miring ke arah selatan. Sedangkan akifer dalam ditemukan pada kedalaman 50-150 m.

\subsubsection{Analisis Curah Hujan}

Secara umum curah hujan di Kota Denpasar cukup bervariasi sepanjang tahun 2015 - 2016. Berdasarkan distribusi bulanan pada bulan Januari merupakan puncak musim hujan pada tahun 2015, sedangkan pada tahun 2016 puncak hujan berada pada bulan Februari. Puncak musim kemarau pada tahun 2015 terjadi pada bulan Oktober, sedangkan untuk tahun 2016 terjadi pada bulan April. Data curah hujan yang tersedia akan dilakukan analisis dengan interpolasi menggunakan metode Inverse Distance Weighted (IDW) yang didapatkan berdasarkan data curah hujan bulanan selama kurun waktu 2008 - 2017 dari Pos Sanglah dan Pos Sumerta. Persebaran data curah hujan disetiap wilayah Kota Denpasar disajikan pada Tabel 3 di bawah ini.

Tabel 3. Tingkat Persebaran dan Skoring Rata-Rata Curah Hujan

\begin{tabular}{ccccc}
\hline No. & Curah Hujan & Rata - rata $(\mathbf{m m} / \mathbf{b} \mathbf{l n})$ & Skor & Tingkat Kerawanan \\
\hline 1 & Tinggi & $164,4-166,2$ & 6 & Tinggi \\
2 & Sedang & $162,5-164,3$ & 4 & Sedang \\
3 & Rendah & $160,7-162,5$ & 2 & Rendah \\
\hline
\end{tabular}

\subsubsection{Analisis Kemiringan Lereng}

Kota Denpasar memiliki morfologi landai dengan kemiringan lereng sebagian besar berkisar antara 0-5\% namun di bagian tepi kemiringannya bisa mencapai 8\%. Bentuk permukaan Kota Denpasar datar dan landai pada kisaran 0-8\% yang melandai ke arah selatan. Namun kondisi kemiringan lereng Kota Denpasar yang termasuk datar dan melandai menyebabkan air sangat mudah untuk tergenang. Berdasarkan analisis data DEM Spaceborne Thermal Emission and Reflection Radiometer (DEM ASTER) tahun 2016 yang disajikan pada Tabel 4. Tabel tersebut menunjukkan jika tingkat kemiringan Kota Denpasar dengan 
persentase $61,88 \%$ dari luas Kota Denpasar memiliki kemiringan 0-3\% yang sebagian besar berada pada Kecamatan Denpasar Selatan dan Kecamatan Denpasar Timur.

Tabel 4. Skoring Analisis Kemiringan Lereng

\begin{tabular}{cccrrrc}
\hline No. & $\begin{array}{c}\text { Kemiringan } \\
\text { Lereng }\end{array}$ & $\begin{array}{c}\text { Ketinggian } \\
(\mathbf{m d p l})\end{array}$ & $\begin{array}{c}\text { Luas Area } \\
\left(\mathbf{K m}^{2}\right)\end{array}$ & $\begin{array}{c}\text { Persentase } \\
(\mathbf{\%})\end{array}$ & Skor & $\begin{array}{c}\text { Tingkat } \\
\text { Kerawanan }\end{array}$ \\
\hline 1 & $0-3 \%$ & $0-25$ & 79,03 & $61,88 \%$ & 9 & Tinggi \\
2 & $3-8 \%$ & $25-50$ & 38,97 & $30,51 \%$ & 6 & Sedang \\
3 & $>8 \%$ & $>50$ & 9,72 & $7,61 \%$ & 3 & Rendah \\
\hline
\end{tabular}

Sumber: Pengolahan Data (2018)

\subsubsection{Analisis Penggunaan Lahan}

Berdasarkan interpretasi citra Landsat 8 tahun 2015 dan 2016 menggunakan kombinasi dari band

4 , band 3, dan band 2 yang merupakan kombinasi band terbaik dalam mengklasifikasikan penggunaan lahan. Secara visual di Kota Denpasar teridentifikasi menjadi 3 kelas penggunaan lahan. Kelas penggunaan lahan tersebut terdiri dari lahan terbuka/hijau, lahan terbangun (kerapatan rendah), dan lahan terbangun (kerapatan tinggi). Menurut Foody et al. (1992) metode maximum likelihood classification (MLC) digunakan untuk mengklasifikasikan penggunaan lahan data OLI dan merupakan metode yang paling umum digunakan dalam klasifikasi data remote sensing. Analisis data Landsat 8 dengan metode pengkelas MLC ini perlu dilakukan uji akurasi untuk klasifikasi penggunaan lahan.

Akurasi ketelitian dengan Kappa dihitung menggunakan sampel data klasifikasi penggunaan lahan dan data referensi dari lapangan yang dimasukkan dalam matriks konfusi. Hasil ditunjukkan akurasi ketelitian yaitu kelas lahan terbangun (kerapatan rendah) memiliki producer akurasi yang paling rendah (72,7\%) dan memiliki konfusi maksimum dengan lahan terbuka/hijau. Hal ini disebabkan karena lahan terbangun (kerapatan rendah) pada kenyataannya merupakan bangunan dengan jarak lebih luas dengan bangunan lain atau dikelilingi oleh lahan terbuka/hijau yang cukup luas sehingga beberapa area lahan terbuka/hijau kadang menunjukkan kelas lahan terbangun (kerapatan rendah) seperti pada hasil MLC tahun 2015 kelas lahan terbangun (kerapatan rendah) lebih besar dibandingkan dengan tahun 2016, namun lahan terbuka/hijau pada hasil MLC tahun 2015 menunjukkan jumlah yang lebih kecil dibandingkan tahun 2016. Kelas lainnya terpisahkan dengan baik serta dengan tingkat akurasi user dan producer.

Hasil akurasi overall klasifikasi diperoleh 92\% sedangkan pada akurasi Kappa yang diperoleh adalah $89 \%$. Menurut United States Geological Survey (USGS) telah ditetapkan tingkat ketelitian untuk klasifikasi atau interpretasi minimum untuk tingkat keakuratan data remote sensing yaitu lebih dari $85 \%$. Akurasi Kappa dianjurkan untuk digunakan karena menghitung semua data dalam matriks konfusi. Berdasarkan dari hasil nilai akurasi ketelitian yang diperoleh sudah cukup untuk memenuhi syarat yang ditetapkan oleh USGS. Oleh sebab itu, hasil dari metode MLC pada citra Landsat 8 dalam klasifikasi penggunaan lahan di Kota Denpasar dapat digunakan sebagai peta penggunaan lahan.

Berdasarkan hasil analisis data Citra Landsat 8 OLI lahan terbangun yang berada di tengah perkotaan semakin meningkat dengan adanya pembangunan yang tidak terkendali. Beberapa lahan terbuka/hijau yang berada di tengah perkotaan semakin hilang digantikan dengan bangunan-bangunan permanen. Alih fungsi lahan tersebut bahkan sangat terlihat dari tahun 2015 hingga tahun 2016. Keadaan tersebut bisa menjadi pemicu terjadinya banjir ketika air meluap di kawasan kedap air, dalam artian kawasan tersebut tidak memiliki kemampuan untuk menyerap air dalam waktu singkat. Kejadian ini biasanya banyak terjadi ke kawasan perkotaan yang sebagian besar alas tanahnya sudah memakai paving, aspal dan/atau beton. Permukiman di perkotaan yang memiliki kerapatan pembangunan yang tinggi sehingga alas tanahnya sudah banyak tertutup dan menyisakan kawasan resapan air yang sangat sedikit sekali. Hasil dari klasifikasi analisis di atas disajikan pada Tabel 5 . 
Tabel 5. Skoring Peta Tutupan Lahan Tahun 2015 dan 2016

\begin{tabular}{|c|c|c|c|c|c|}
\hline No. & Penggunaan Lahan (PL) & Luas Area $\left(\mathrm{Km}^{2}\right)$ & Persentase (\%) & Skor & $\begin{array}{c}\text { Tingkat } \\
\text { Kerawanan }\end{array}$ \\
\hline \multicolumn{6}{|c|}{ Tahun 2015} \\
\hline 1 & Lahan Terbangun (Tinggi) & 48,63 & 38,97 & 3 & Tinggi \\
\hline 2 & Lahan Terbangun (Rendah) & 33,63 & 26,95 & 2 & Sedang \\
\hline 3 & Lahan Terbuka/Hijau & 42,51 & 34,07 & 1 & Rendah \\
\hline \multicolumn{6}{|c|}{ Tahun 2016} \\
\hline 1 & Lahan Terbangun (Tinggi) & 62,18 & 49,84 & 3 & Tinggi \\
\hline 2 & Lahan Terbangun (Rendah) & 18,79 & 15,07 & 2 & Sedang \\
\hline 3 & Lahan Terbuka/Hijau & 43,78 & 35,09 & 1 & Rendah \\
\hline
\end{tabular}

\subsubsection{Analisis Kondisi Kebencanaan}

Kota Denpasar berpotensi menjadi kota yang terancam banjir jika tidak dilakukan evaluasi terhadap kejadian bencana banjir sejak dini. Selama tahun 2015 Dinas Pekerjaan Umum Kota Denpasar mencatat terdapat 26 titik banjir/genangan yang tersebar di wilayah Kota Denpasar. Lokasi titik genangan bertambah maupun meluas di beberapa area seperti Jl. Kargo - Pidada, Jl. Gunung Batur-Rinjani, Banjar Tegal Harum, Jl. Pura Demak, Abian Timbul dan Sari Gading, Jl. Ratna-Kamboja-Kenyeri-Suli, Jl. Noja, Jl. Kapten Agung, Jl. Tukad Batanghari-Yeh Aya-Watu Renggong, SD 12 Jl. Hangtuah, Jl. Gemitir Kesiman Kertalangu, Jl. Bedugul-Pakerisan-Dewata, Kepaon, Pemogan, Griya anyar, Jl. Nakula, Jl. Gatsu VI, Jl. Nangka-Antasura-Astasura, Padang Sambian Kaja dan Kelod, Jl. Siulan, dan Jl. By Pass Ngurah Rai (Makro).

Kondisi titik banjir atau genangan semakin memburuk pada tahun 2016 terdapat 13 titik banjir/genangan yang tersebar di wilayah Kota Denpasar dengan beberapa lokasi yang sama dengan tahun sebelumnya, yaitu Jl. Perempatan Cokroaminoto, Jl. Teuku Umar, Jl. Buluh Indah, Jl. Gunung Agung, Jl. Gunung Payung, Lingkungan Perum. Asri dan Perum. Purnawira, Jl. Tangkuban Perahu, Lingkungan Bumi Ayu, Jl. Tukad Bilok, Jl. Danau Tempe, Jl. P. Serangan dan Satelit Sanglah, dan Mitra 10 Pemogan.

Menurut analisis dari data wawancara dan hasil survei yang diperoleh beberapa permasalahan yang terjadi pada titik banjir/genangan tersebut dipengaruhi kondisi saluran drainase seperti adanya pendangkalan saluran akibat endapan dari hilir, terbatasnya jalan inspeksi sepanjang saluran (terutama di bagian hulu), saluran drainase di sekitar pemukiman yang tersumbat oleh sampah, pembuangan utama yang memiliki kemiringan relatif rendah sehingga mempercepat sedimentasi, kemiringan saluran yang relatif kecil, dan saluran pembuangan utama selain berfungsi sebagai saluran drainase juga masih berfungsi sebagai saluran pembawa air untuk kebutuhan irigasi (subak).

\subsubsection{Analisis Kerawanan Banjir Berbasis Sistem Informasi Geografis (SIG)}

Tingkat kerawanan banjir di Kota Denpasar menghasilkan tiga klasifikasi kelas. Kelas tingkat kerawanan banjir tersebut terdiri dari kerawanan banjir rendah atau aman, kerawanan banjir sedang atau waspada dan kerawanan banjir tinggi atau berbahaya. Tingkatan kelas kerawanan banjir diperoleh dari hasil nilai bobot dan skor pada setiap faktor dan variabel yang digunakan. Parameter yang digunakan yaitu penggunaan lahan, kemiringan lereng, rata-rata curah hujan tahunan, dan kedalaman air tanah. Berdasarkan hasil analisis, wilayah banjir dengan kondisi tingkat kerawanan banjir rendah atau aman pada tahun 2015 mempunyai luasan $0,83 \mathrm{Km}^{2}$ atau $0,65 \%$ dari luas wilayah Kota Denpasar, sedangkan pada tahun 2016 kondisi tersebut meningkat menjadi $3,54 \mathrm{Km}^{2}$ atau 2,77\% dari luasan wilayah Kota Denpasar. Luasan banjir dengan kondisi tingkat kerawanan banjir sedang atau waspada pada tahun 2015 mencapai $50,77 \mathrm{Km}^{2}$ atau sekitar 39,74 \% dari luas wilayah Kota Denpasar, sedangkan pada tahun 2016 kondisi tersebut menurun menjadi $45,98 \mathrm{Km}^{2}$ atau 35,99\% dari luasan wilayah Kota Denpasar. Sedangkan kondisi tingkat kerawanan tinggi atau berbahaya pada tahun 2015 mencapai 76,17 Km² atau 59,62 \% dari luas wilayah Kota Denpasar, 
sedangkan pada tahun 2016 kondisi tersebut meningkat hingga 78,24 Km² atau 61,24\% dari luasan wilayah Kota Denpasar. Hasil peta daerah rawan banjir Kota Denpasar disajikan pada Gambar 2 berikut ini.

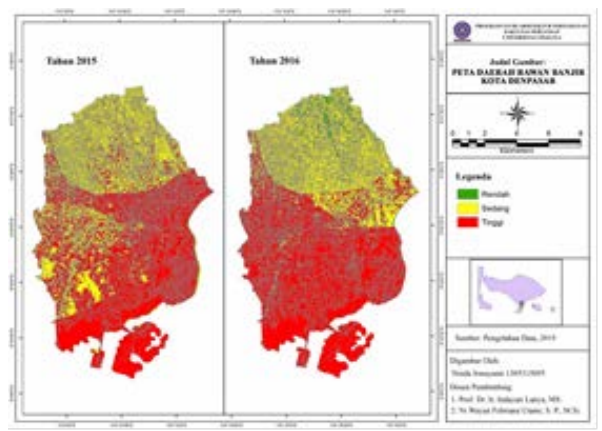

Gambar 2. Peta Daerah Rawan Banjir Kota Denpasar Tahun 2015 dan 2016

Berdasarkan analisis di atas maka tingkat kerawanan banjir yang ada di Kota Denpasar disebabkan oleh beberapa faktor. Faktor-faktor tersebut dapat dikategorikan dalam dua faktor yaitu faktor internal dan faktor eksternal. Faktor internal yang dimaksud adalah kondisi topografi datar dan melandai merupakan kondisi yang mudah memicu terjadinya genangan banjir, karena limpasan air yang jatuh akan mencari daerah yang lebih rendah. Topografi yang cenderung landai seperti pada Kota Denpasar bagian selatan sangat berpotensi terjadinya genangan. Kemudian kondisi kedalaman air tanah. Menurut ilmu hidrogeologi, akifer merupakan suatu batuan/formasi yang mempunyai kemampuan untuk menyimpan dan mengalirkan air dalam tanah dengan jumlah yang signifikan. Untuk dapat berfungsi sebagai akifer, suatu batuan haruslah berpori atau berongga agar berhubungan satu sama lain sehingga dapat menyimpan dan membiarkan air bergerak dari rongga ke rongga. Adapun kondisi penggunaan lahan yang tidak terkendali sehingga beberapa wilayah semakin tidak memiliki daerah resapan air yang dapat menjaga keseimbangan wilayah perkotaan. Faktor lain yang sangat berpengaruh dalam mengendalikan banjir pada kawasan perkotaan yaitu kondisi drainase yang terjaga dan terawat dapat mengurangi risiko banjir di perkotaan yang memiliki kepadatan bangunan tinggi. Kondisi drainase belum berfungsi secara optimal dan kurang partisipasi masyarakat maupun pemerintah dalam memelihara dan merawat drainase.

Untuk faktor eksternal, yang paling berpengaruh terhadap terjadinya banjir yaitu faktor keadaan sosial yang merupakan pola hidup dalam masyarakat Kota Denpasar yang masih belum bisa menghargai maupun menjaga lingkungan di sekitarnya dan kurang memperhatikan atau antisipasi terhadap lingkungan hidupnya pada bencana yang akan terjadi nantinya. Lingkungan permukiman di perkotaan yang sedikit memiliki lahan terbuka/hijau yang terdapat berbagai vegetasi sebagai peresap air, semakin banyaknya sampah yang dibuat oleh masyarakat menjadi akibat buruknya sanitasi lingkungan. Selain itu masih terdapat perilaku masyarakat yang masih menjadikan drainase sebagai tempat untuk membuang sampah yang akan berakibat tersumbatnya aliran air dan akan mengurangi kemampuan tanah untuk menyerap air.

\subsection{Konsep Zonasi}

Sesuai segmentasi kawasan berdasarkan pendekatan mitigasi bencana dengan mempertimbangkan kondisi berbagai parameter yang memiliki kaitan terhadap penyebab terjadinya banjir di Kota Denpasar. Diusulkan konsep zonasi yang dirujuk dari Peraturan Presiden Republik Indonesia Nomor 45 Tahun 2011 tentang Rencana Tata Ruang Kawasan Perkotaan Denpasar, Badung, Gianyar, dan Tabanan, sebagai berikut:

\subsubsection{Konsep Mitigasi Bencana}

Dalam mengkaji konsep mitigasi bencana perlu dipahami terlebih dahulu mengenai pengertian bencana (disaster) dengan bencana banjir (flood disaster). Menurut Raharjo (2009) banjir merupakan suatu keluaran (output) dari hujan (input) yang mengalami proses dalam sistem lahan yang berupa luapan air yang berlebih. Mitigasi bencana banjir secara pasif dapat dilakukan melalui penelitian-peneltian ilmiah yang berbasis pengetahuan dan teknologi dengan pendekatan keruangan (spatial). Mitigasi ini menghasilkan panduan berupa peta-peta kawasan rawan banjir pada suatu wilayah, yang dapat dijadikan bahan rujukan 
untuk melakukan mitigasi bencana banjir secara aktif (Hermon, 2010). Konsep mitigasi yang ditawarkan sebagai acuan dalam membuat konsep zonasi berbasis mitigasi bencana, yaitu:

1. Area Kerawanan Rendah

Area kerawanan rendah yang dimaksud yaitu kawasan yang terdiri dari kawasan budidaya dengan tingkat kerawanan banjir yang rendah. Area kerawanan tinggi dengan hasil analisis tingkat kerawanan banjir yang memiliki nilai 2-11 poin dengan luas $0.83 \mathrm{~km}^{2}$. Sesuai dalam Perpres No. 45 Tahun 2011 pada pasal 95, pasal 96, pasal 98, dan pasal 99. Aturan resmi dalam penentuan zonasi kawasan budi daya pada area kerawanan rendah di dalamnya meliputi kawasan perumahan yang memiliki kepadatan sedang hingga rendah dan kawasan pertanian di Desa Kesiman, Desa Kesiman Pentilan, dan Desa Kesiman Kertelangu, kawasan untuk kegiatan kepariwisataan, kawasan sebaran daya tarik wisata, dan kawasan industri dalam mendukung pariwisata di Desa Dangin Puri Kangin, Desa Dangin Puri Kaja, Desa Tonja, Desa Penatih, dan Desa Penatih Dangin Puri. Kawasan pertahanan dan keamanan negara, kawasan kegiatan olahraga, kawasan untuk daerah sosial, budaya dan kesenian di Desa Sumerta, Desa Sumerta Kaja.

2. Area Kerawanan Sedang

Area kerawanan sedang yang dimaksud yaitu kawasan yang didalamnya terdapat kawasan budi daya dengan tingkat kerawanan banjir yang sedang. Area kerawanan sedang dengan hasil analisis tingkat kerawanan banjir yang memiliki nilai $12-21$ poin dengan luas $50,77 \mathrm{~km}^{2}$. Sesuai dalam Perpres No. 45 Tahun 2011 pada pasal 95, pasal 96, dan pasal 99. Aturan resmi dalam penentuan zonasi kawasan budi daya pada area kerawanan sedang meliputi kawasan perumahan kepadatan tinggi hingga sedang di Desa Pemogan, Desa Sesetan, Desa Sanur, dan Desa Panjer, kawasan pemerintahan dalam skala kabupaten, kawasan pemerintahan dalam skala kecamatan, kawasan pertanian di Desa Peguyangan, kawasan untuk kegiatan kepariwisataan, kawasan sebaran daya tarik wisata, kawasan industri untuk mendukung pariwisata, dan kawasan perdagangan dan jasa di Desa Ubung, Desa Ubung Kaja, Desa Dangin Puri Kangin, Desa Dangin Puri Kauh, Desa Dangin Puri kaja, dan Desa Dangin Puri, kawasan kesehatan, kawasan untuk pendidikan tinggi, kawasan sosial, budaya dan kesenian, dan kawasan untuk olahraga di Desa Dauh Puri Kangin, Desa Desa Dauh Puri, Desa Dauh Puri Kaja, kawasan pertahanan dan keamanan negara, di Desa Pemogan dan Desa Sesetan.

3. Area Kerawanan Tinggi

Area kerawanan tinggi ditujukkan pada kawasan lindung dan kawasan budidaya yang memiliki tingkat kerawanan banjir yang tinggi. Area kerawanan tinggi dengan hasil analisis tingkat kerawanan banjir yang memiliki nilai 22-30 poin dengan luas 76,17 Km². Sesuai dalam Perpres No. 45 Tahun 2011 pada pasal 82, pasal 83, pasal 84 , pasal 86, pasal 87 ayat (3), pasal 95, pasal 96, dan pasal 97 dalam aturan resmi dalam penentuan zonasi untuk kawasan lindung dan kawasan budi daya pada area kerawanan tinggi ini di dalamnya meliputi sempadan sungai di sepanjang Tukad Ayung, Tukad Badung, dan Tukad Mati, sempadan pantai di Pantai Sanur, Pantai Mertasari, Pantai Serangan, dan lainnya, kawasan sekitar danau/waduk di Waduk Muara, ruang terbuka hijau (RTH) kota di Taman Kota Lumintang, Lapangan Niti Mandala Renon, dan Lapangan Puputan Badung, kawasan suci, taman wisata alam, taman hutan raya di Taman Hutan Raya Ngurah Rai, kawasan perumahan kepadatan tinggi hingga sedang, kawasan pemerintahan skala kabupaten, kawasan pemerintahan skala kecamatan, kawasan pendidikan tinggi, kawasan pertanian, kawasan untuk kegiatan kepariwisataan, kawasan sebaran daya tarik wisata, kawasan perdagangan dan jasa, kawasan kesehatan, dan kawasan lainnya berada di Kecamatan Denpasar Selatan, Kecamatan Denpasar Timur, dan Kecamatan Denpasar Barat.

\subsubsection{Konsep Zonasi Berbasis Mitigasi Bencana}

Zonasi pada kawasan perkotaan di Kota Denpasar ini mempertimbangkan tingkat kerawanan bencana banjir dengan berbasis mitigasi bencana. Mitigasi bencana dapat diterjemahkan dalam konteks penataan ruang sebagai alat untuk mencegah/menghindari/menghilangkan bahaya (hazard), mengurangi tingkat kerentanan, dan meningkatkan ketahanan dari suatu wilayah/kawasan tertentu. Implementasinya dapat diwujudkan dalam Rencana Tata Ruang Wilayah yang dikategorikan sebagai salah satu alat mitigasi bencana pasif. Dalam mendukung zona-zona yang telah ditetapkan maka dibutuhkan sebuah konsep zonasi berbasis mitigasi bencana banjir di Kota Denpasar. Konsep zonasi berbasis mitigasi bencana banjir yang ditawarkan akan disajikan pada Gambar 3, yaitu: 


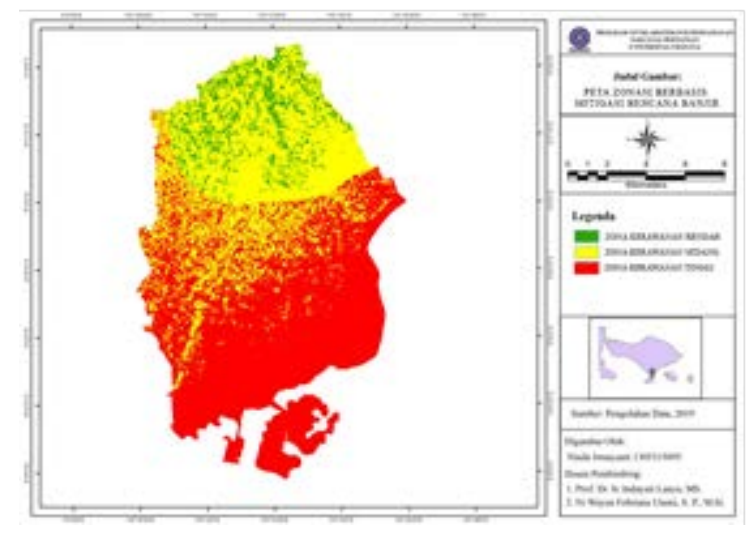

Gambar 3. Peta Zonasi Kawasan Perkotaan Berbasis Mitigasi Bencana Banjir

\section{Zona Kerawanan Rendah}

Zona kerawanan rendah ini merupakan kawasan dengan mengacu pada konsep mitigasi bencana pada area kerawanan rendah yang memiliki tingkat kerawanan banjir rendah. Zona ini merupakan permukiman perdesaan sebagai kawasan yang memiliki kualitas sedang untuk pelayanan prasarana dan sarana, kualitas rendah dalam daya dukung lingkungannya, serta bangunan gedung horisontal dengan intensitas sedang dan bangunan gedung vertikal yang terbatas. Zona ini juga merupakan kawasan pertanian dengan irigasi teknis yang ada pada kawasan permukiman pedesaan yang berada di Kecamatan Denpasar Utara seperti pada subak sembung yang berada di Desa Peguyangan. Dan kawasan lainnya seperti kawasan industri perdagangan dan jasa yang berada di Jl. Gatot Subroto Timur Desa Penatih dan Desa Kesiman, Kecamatan Denpasar Timur, kawasan industri perdagangan di Jl. Cokroaminoto Desa Ubung, Denpasar Utara, dan kawasan industri lainnya di Jl. Kebo Iwa Utara Desa Padang Sambian Kaja, Kecamatan Denpasar Barat.

\section{Zona Kerawanan Sedang}

Zona kerawanan sedang ini merupakan kawasan dengan mengacu konsep mitigasi bencana pada area kerawanan sedang yang tingkat kerawanan banjirnya sedang. Zona kerawanan sedang merupakan kawasan pendukung zona sekitarnya dengan tujuan sebagai penunjang kawasan yang terdampak seperti Kawasan pemerintahan Kota Denpasar yang berada di Desa Dauh Puri Kaja, kawasan pariwisata seperti perhotelan, pusat perbelanjaan, maupun kawasan industri pendukung pariwisata di sepanjang Jalan Gatot Subroto Barat, Jl. Cokroaminoto Selatan, Jl. Thamrin, dan kawasan lainnya. Zona kerawanan sedang ini berada di sebagian Kecamatan Denpasar Utara, sebagian Kecamatan Denpasar barat, sebagian Kecamatan Denpasar Timur, dan sebagian kecil Kecamatan Denpasar Selatan di Kota Denpasar seperti pada sekitar Jl. Imam Bonjol.

\section{Zona Kerawanan Tinggi}

Zona kerawanan tinggi ini mengacu pada konsep mitigasi bencana pada area kerawanan tinggi dengan tingkat kerawanan terhadap bencana banjir yang tinggi. Zona kerawanan tinggi juga merupakan kawasan perlindungan setempat dengan tujuan melindungi pantai, sungai, jurang, waduk, kawasan suci, kawasan tempat suci, dan RTH dari kegiatan budi daya yang dapat mengganggu kelestarian fungsinya. Sempadan pantai yang dimaksud berada pada Kecamatan Denpasar Selatan dan Kecamatan Denpasar Timur. Sempadan sungai yang berada di Tukad Ayung, Tukad Badung, dan Tukad Mati. Kawasan sekitar waduk berada di Waduk Muara di Kecamatan Denpasar Selatan.

Taman Hutan Raya (Tahura) Ngurah Rai seluas $13,75 \mathrm{~km}^{2}$ merupakan kawasan konservasi dan perlindungan ekosistem pesisir berupa kawasan hutan pantai berhutan bakau, yang termasuk ke dalam sebagian Kecamatan Denpasar Selatan, Kota Denpasar dan sebagian Kecamatan Kuta dan Kecamatan Kuta Selatan, Kabupaten Badung. Kawasan Pariwisata di Pantai Sanur terdapat di Kecamatan Denpasar Timur. Zona kerawanan tinggi terdapat di sebagian Kecamatan Denpasar Utara, sebagian Kecamatan 
Denpasar barat, sebagian Kecamatan Denpasar Timur, dan Kecamatan Denpasar Selatan di Kota Denpasar.

\section{Simpulan dan Saran \\ 4.3 Simpulan}

Karakteristik fisik spasial Kota Denpasar terdiri dari empat parameter yaitu: hidrogeologi, curah hujan, kemiringan lereng, dan penggunaan lahan. Dari pemetaan seluruh parameter tersebut diperoleh hasil peta rawan bencana banjir di Kota Denpasar yang terdiri dari tingkat kerawanan rendah, sedang dan tinggi. Pada tahun 2015 diperoleh tingkat kerawanan rendah seluas 0,63\%, tingkat kerawanan sedang seluas 39,74\%, dan tingkat kerawanan tinggi 59,63\% dari luas Kota Denpasar. Tahun 2016 mengalami perubahan luas tingkat kerawanan rendah meningkat menjadi 2,77\%, tingkat kerawanan sedang menurun menjadi $36,0 \%$, dan tingkat kerawanan tinggi meningkat menjadi 61,23\% dari luas Kota Denpasar.

Konsep Zonasi pada kawasan perkotaan di Kota Denpasar mempertimbangkan tingkat kerawanan bencana banjir dengan berbasis mitigasi bencana. Berdasarkan hasil analisis kebencanaan, nilai yang diperoleh yaitu 2-30 poin. Parameter yang menjadi kendala dalam menentukan zona kerawanan banjir ini yaitu pada data penggunaan lahan masih perlu adanya uji akurasi lainnya untuk mendapatkan ketelitian dari data spasial dengan kondisi sebenarnya yang lebih akurat. Konsep zonasi berbasis mitigasi bencana yang ditawarkan yaitu: 1) Zona kerawanan tinggi, zona dengan hasil analisis tingkat kerawanan banjir tinggi yang memiliki nilai 22-30 poin ini perlu melindungi kawasan lindung dan kawasan budi daya dengan melakukan pembatasan dalam pembangunan yang dapat mengganggu kelestarian fungsi lingkungannya dan dapat melakukan penanggulangan banjir dengan menyediakan kolam penampungan air hujan secara merata di setiap kawasan yang rawan genangan air dan/atau rawan banjir; 2) Zona kerawanan sedang, zona dengan hasil analisis tingkat kerawanan banjir sedang yang memiliki nilai 12-21 poin ini menjadi kawasan penunjang dari zona lainnya dalam mencegah bencana banjir dan dapat memulai dari menanggulangi resiko bencana banjir agar tidak meluas dengan melakukan teknik Artificial Recharge yang dapat membantu secara mandiri area perhotelan, pusat perbelanjaan, pemerintahan, maupun industri lainnya dalam menyerap langsung air ke dalam tanah dan tersimpan di air tanah dalam.; 3) Zona kerawanan rendah, zona dengan hasil analisis tingkat kerawanan banjir rendah yang memiliki nilai 2-11 poin merupakan kawasan permukiman, kawasan pertanian, dan kawasan penunjang lainnya perlu adanya pengendalian pembangunan yang maksimal dan menjaga agar kawasan resapan air tetap ada.

\subsection{Saran}

Pemerintah dan masyarakat perlu bekerjasama memelihara lingkungan dan memonitor pemanfaatan ruang pada wilayah studi. Dengan melakukan penelitian lebih lanjut pada wilayah studi, khususnya pada analisis kerawanan banjir dengan memasukkan kondisi dari perilaku aliran saluran terbuka seperti sungai dan selokan dengan menggunakan ilmu terapan lainnya seperti hidraulika, sehingga konsep zonasi berbasis mitigasi bencana banjir yang dihasilkan dapat lebih valid dan dapat dijadikan acuan dalam pengembangan dan pembangunan wilayah perkotaan.

\section{$5 \quad$ Daftar Pustaka}

Foody, G. M., Campbell, N.A., Trodd, N.M., \& Wood, T.F. (1992). Derivation and applications of probabilistic measures of class membership from the maximum-likelihood classification. Photogrammetric Engineering and Remote Sensing. 58: 1335-1341.

Jaya, I.N.S. (2010). Analisis Citra Digital Perspektif Penginderaan Jauh untuk Pengelolaan Sumber Daya Alam. Fakultas Kehutanan Institut Pertanian Bogor.

Hermon, D. (2012). Mitigasi Bencana Hidrometeorologi: Banjir, Longsor, Ekologi, Degradasi lahan, Putting beliung, Kekeringan. Padang: UNP Press.

Pemerintah Republik Indonesia. (2011). Peraturan Presiden Nomor 45 Tahun 2011 tentang Rencana Tata Ruang Kawasan Perkotaan Denpasar, Badung, Gianyar, Dan Tabanan. Pemerintah Republik Indonesia. Jakarta. 
Raharjo, P.D. (2009, Mei 29). Permodelan Hidrologi Untuk Identifikasi Daerah Rawan Banjirdi Sebagian Wilayah Surakarta Menggunakan SIG (Sistem Informasi Geografi). Retrieved September 22, 2016, from http://puguhdraharjo.wordpress.com/

Salain, R. (2015, April 23). Focus Group Discussion Analisis Banjir Kota Denpasar Denpasar. Retrieved April 1, 2019, from http://ppebalinusra.menlh.go.id/focus-group-discussion-analisis-banjir-kota-denpasardenpasar-23-april-2015.html

United States Geological Survey. (2016). Landsat 8 (L8) Data Users Handbook. Department Of The Interior U.S. Geological Survey. Retrieved August 12, 2018, from https://www.usgs.gov/landresources/nli/landsat/landsat-8-data-users-handbook 